American Journal of Animal and Veterinary Sciences 7 (1): 21-27, 2012

ISSN 1557-4555

(C) 2012 Science Publications

\title{
The Use of Silver Vine (Actinidia Polygama Maxim, Family Actinidiaceae) as an Enrichment Aid for Felines: Issues and Prospects
}

\author{
${ }^{1}$ Charles I. Abramson, ${ }^{1}$ Angela Lay, \\ ${ }^{2}$ Timothy J. Bowser and ${ }^{1}$ Christopher A. Varnon \\ ${ }^{1}$ Departments of Psychology and Zoology, \\ Laboratory of Comparative Psychology and Behavioral Biology, \\ ${ }^{2}$ Robert M. Kerr Food and Agricultural Products Center, \\ Oklahoma State University, 116 N. Murray, Stillwater, OK, 74078, USA
}

\begin{abstract}
Problem statement: This study highlights the potential of using silver vine as an enrichment additive for felines. Approach: A literature review was conducted on the use of silver vine since 1973. The articles were categorized into studies concerned with behavior, biological effects, beneficial uses, plant and chemical studies. Results: We found surprisingly few studies that utilized silver vine. There were only four studies concerned with the effect of silver vine on behavior and no behavior studies have been conducted since 1997. Only one study was found in the biological domain that explored the effects of silver vine on amygdala (which was thought to affect sexual behavior) by surgically removing the amygdala. No studies in the biological domain were found after 1979. In contrast to studies of biology and behavior, the literature contained sixteen articles on various aspects of plants with none published since 2008. Articles included studies on root pressure and shoot development, freezing temperatures and the cold-hardiness of the plant. Others explored the fruit of the plant and relationship with matatabi fruit gall midge, Pseudasphondylia matatabi that infected them. Eighteen articles on the beneficial uses of silver vine were found with none published since 2009 and twenty-two articles concerned with the chemistry of silver vine were found with two published since 2008. These articles concerned the organic chemistry of compounds found in the plant, as well as the chemistry that occurred when $P$. matatabi infected the fruit, which produced new chemical compounds in the plant. In conducting the literature review, we uncovered an error in the literature where silver vine was considered addictive to cats. We subsequently showed that no scientific data exists demonstrating any purported addictive properties of silver vine. The original conclusion that silver vine had addictive properties was based solely upon a single uncontrolled anecdote that, unfortunately, had been perpetuated in the literature to the present day. Conclusion: Behavioral research on silver vine as an aid to enrichment devices for felines is an unexplored area. Silver vine has much potential for use with enrichment devices and is very easy to use.
\end{abstract}

Key words: Silvervine, matatabi, cat, leyhausen

\section{INTRODUCTION}

Enrichment devices are designed to enhance the quality of animal-human interactions and have become an active area of research (Shepherdson, 1998; Ellis, 2009; Tarou and Bashaw, 2007; Shyne, 2006). Devices for home use and those used in zoos and animal parks attempt to stimulate an animal's senses and cognitive abilities by manipulating objects in their environment.

In addition to enhancing animal-human interactions, enrichment devices can be used by veterinarians to improve the physiological well-being of sick animals such as those suffering from arthritis and obesity.

Enrichment also improves the psychological wellbeing of animals. One meta-analysis of 63 studies on effects of enrichment of mammals at zoos, 13 of which were on felines, found that enrichment decreased abnormal and stereotypical behaviors in $90 \%$ of the studies (Shyne, 2006). Many reports of feline enrichment focus on the use of food as enrichment. Some studies reported an increase in desirable activity, such as hunting in African lions (Powell, 1995), African

Corresponding Author: Charles I. Abramson, Departments of Psychology and Zoology,

Laboratory of Comparative Psychology and Behavioral Biology, Oklahoma State University,

116 N. Murray, Stillwater, OK 74078, USA Fax: 405 744-8067 
leopards (Markowitz et al., 1995) and fishing cats (Sheperdson et al., 1993). Other studies reported both an increase in desirable activity and a reduction in stereotypical behaviors using food enrichment such as live fish and horse leg bones in African lions and Sumatran tigers (Bashaw et al., 2003). Inedible enrichment, such as spices, has also been shown to increase desirable activity and decrease stereotypies in several feline species (Skibel et al., 2007). Other objects not associated with food, such as Boomer Balls ${ }^{\circledR}$ and other plastic toys may also induce desirable activity such as hunting behaviors (Mellen and Shepherdson, 1997).

In addition to decreasing undesirable behaviors, enrichment may also contribute to visitor interest through an increase in activity. Across institutions and species, visitors perceive active animals to be more interesting than inactive animals (Bitgood et al., 1988). Margulis et al. (2003) reported that an increase in activity of six feline species produced an increase in visitor interest and number. They suggest that providing enrichment for felines may increase activity and in turn increase visitor interest.

One of the keys to a successful device is maintaining the animal's interest in the enrichment item. This can be accomplished, for example, by finding a stimulus that can be used to stimulate the senses and be rewarding to the animal. Mellen and Shepherdson (1997) suggest that no single type of enrichment is always effective and that managers must always search for new options for enrichment. The use of silver vine as feline enrichment provides a previously unexplored option.

The purpose of this study is to suggest that silver vine (Actinidia polygama Maxim, Family Actinidiaceae) be evaluated as an enrichment aid. Silver vine is a deciduous shrub indigenous to Japan and Korea and is commonly used in Asian medicine. Anecdotal evidence suggests that it is highly attractive to cats as evidenced by salivation and increased activity (Shoyama et al., 1998). A silver vine branch is usually given to a cat to stimulate a response (Katahira and Tsukahara, 1974) of salivation, licking, playful rubbing, rolling, treading with hind legs and finally sleeping (Hayashi, 1968). We reviewed the literature on silver vine and suggest avenues for future behavioral research. Of special interest is that we have uncovered an error in the literature that suggested silver vine is addictive to cats. This error has become part of the behavioral literature on silver vine and is based only upon a single anecdotal observation under poorly controlled conditions.
The error mentioned above appeared in the BayerSymposium IV, Psychic Dependence in an article entitled "Addictive Behavior in Free Ranging Animals" by Paul Leyhausen (1973). Leyhausen published numerous scientific papers and books. His research helped to design feline enclosures in many zoos. However, in this particular publication, he recites some of his observations of the effects of silver vine on the large cats of Osaka Zoo. From his observations, he concluded that the cats became addicted to silver vine because "the cats became so eager that the moment they saw the experimenter appear they left everything, including food, sexual intercourse or whatever it was and just ran up to the bars and waited for this smell [of silver vine]" (Leyhausen, 1973). However, there is a flaw in Leyhausen's reasoning, which is admitted by Leyhausen himself. He states that silver vine: (Leyhausen, 1973):

Affected [the cats'] sense of smell and in the end damaged their brains, as my Japanese counterparts told me... the zoo director was not very keen on having sufficient experiments and autopsies made to confirm the results on brain damage statically, because he likes to have animals healthy and alive in their cages. For that reason, this part of the story is anecdotal. There is no experimental statistics proving that the brain is affected.

Unfortunately, this observation has been recited in more recent scientific articles and is written as a scientific truth, such as in Tucker and Tucker (1988) well-known article entitled "Catnip and the Catnip Response". The authors state, "an extract of [silver vine] apparently induces addictive behavior and continual stimulation may produce brain damage in cats," and cite Leyhausen's publication in Psychic Dependence. Because this article is so well known in the study of plants that effect feline behavior, it is cited in an additional 14 scientific articles that may further spread the error (Bernier et al., 2005; Blum et al., 1990; Chizzola, 2006; Frank et al., 2010; Herron, 2001; Ibrahim and El-Moaty 2010; Kelly 1996; Lee et al., 2010; McCaskill, 1997; Weldon 2004; Skaltsa et al., 2000; Zhao et al., 2006; 2007).

\section{MATERIALS AND METHODS}

A content analysis was conducted from June 2010 through August 2010. Scientific articles written in or after $1973(\mathrm{~N}=57)$ containing information on the silver vine plant were coded. The defining year of 1973 was based on the year that the first known published error of 
American J. Animal \& Vet. Sci., 7 (1): 21-27, 2012

silver vine being addictive to cats appeared. Three different search engines were used to search for scientific articles; (1) Oklahoma State University's Library database, (2) Google Scholar and (3) Web of Science. A keyword search was conducted using each search engine. Keywords were: "Actinidia polygama," "silvervine" and "silver vine."

The articles were classified into the following areas based on content: behavior-articles relating to behavioral effects of exposure to silver vine, biologyarticles relating to the effects of exposure on a biological system, beneficial uses-articles relating to any practical use for humans or animals, plant-articles relating to the physiology and ecology of silver vine and chemicalarticles relating to chemistry of compounds found in the plant. Articles that contained the error made by Leyhausen (1973), or the errors further spread by Tucker and Tucker (1988) were noted but not further classified.

\section{RESULTS}

Table 1 summarizes the findings of our literature review (Hayashi, 1968; Baranec and Murin, 2003; Barrero et al., 2005; Sulaiman and Yukawa, 1992; Boldingh et al., 2000; Chat, 1995; Clapperton et al., 1994; Clearwater, 2004; 2006; 2007; Derambure and Hirsch, 1995; Enders and Kaiser, 1997; Hiramatsu et al., 2004; Hirsch, 1979; Hirsch et al., 2001; Hooper et al., 2002; Jung et al., 2003; Katahira and Tsukahara, 1974; Katahira and Iwai, 1975; Katahira et al., 1975; Katahira and Tsukahara, 1978; Katsube et al., 2004; Kawagoe and Suzuki 2004; Kigawa et al., 1992; Kim et al., 2006; Kim et al., 2003; Lai, 2007; Lawes et al., 1995; Lee et al., 2006; Matich et al., 2010; Matsuzawa et al., 1989; 1986; McGhie and Ainge 2002; Otsuka et al., 2003; Patocka and Jakl 2010; Ren et al., 2007; Sakai et al., 1980; Santangelo et al., 2001; Sashida et al., 1992; 1994; Sugawara et al., 1994; Takazawa et al., 2002; Tanaka et al., 1997; Webby et al., 1994; Wuest et al., 1977; Xiao and Hirsch 1996; Xiufen et al., 2004; Yoshizawa et al., 1994; 2000a; 2000b 2002; Zhao et al., 2006, 2007). In the review, we found no articles that support Leyhausen's (1973) suggestion that silver vine is addictive to cats. We also noted that little research regarding the behavioral and biological effects of exposure to silver vine has been conducted. Only four articles were found addressing the effects of silver vine on behavior and only one article was found addressing the biological effects. The majority (93\%) of the articles found related to the biology or ecology of the silver vine plant, its chemical composition, or its practical uses.
Table 1: Number of articles found per year in each category

\begin{tabular}{llllll}
\hline Year & Behavior & Biology & Beneficial Uses & Plant & Chemical \\
\hline $1973-1978$ & 3 & 1 & 00 & 00 & 01 \\
$1979-1984$ & 0 & 0 & 00 & 01 & 03 \\
$1985-1990$ & 0 & 0 & 02 & 00 & 00 \\
$1991-1996$ & 0 & 0 & 03 & 07 & 04 \\
$1997-2002$ & 0 & 0 & 03 & 02 & 07 \\
$2003-2008$ & 0 & 0 & 07 & 06 & 04 \\
$2009-2010$ & 0 & 0 & 01 & 00 & 02 \\
Total & 3 & 1 & 16 & 16 & 21 \\
\hline
\end{tabular}

\section{DISCUSSION}

The results of the literature review suggest that there is much potential for further investigation of silver vine in behavioral research and application. One area that silver vine may be particularly useful is in the enrichment of captive animals.

Silver vine may be used as enrichment in a variety of manners. Small amounts of silver vine may be presented in randomly altering locations throughout the exhibit to encourage an increase in general activity, similar to the use of spices described by Skibel et al. (2007). Silver vine may also be placed in areas that provide the public with a clear view of the animals to increase visitor interest.

Silver vine may be used to encourage felines to interact with other enrichment objects. Mellen and Shepherdson (1997) suggest that hiding food items in enrichment items such as Boomer Balls ${ }^{\circledR}$ may encourage exploration. Applying silver vine to these types of enrichment items provides an alternative to encouraging interaction with food and may have the benefits of not interfering with diet restrictions, being less likely to attract native species such as ants or rodents and a decreased likelihood of the animal ingesting part of the enrichment while attempting to get the food. Repeated associations with silver vine and specific enrichment items may produce a transfer of some of the effects through classical conditioning.

In addition to enrichment, silver vine may also be a potent reinforcer for husbandry behaviors in felines. Husbandry behaviors include training animals to eagerly cooperate with medical procedures such as tactile examinations and blood draws and routine behaviors such as moving between exhibits and holding space. Traditionally, husbandry behaviors are reinforced with food. In some cases food may not be an appropriate reinforcer, such as when the animal is on a restricted diet or uninterested in food due to illness or satiation. In these cases silver vine may be a very useful reinforcer.

Before silver vine can be efficiently employed as enrichment or as a reinforcer for felines, a basic understanding of the effects of silver vine is required. 
One area of future study is the reliability of the effect of silver vine. Repeated presentations of silver vine may lead to a decrease in response, or a complete lack of responding, through a process known as habituation. Thompson and Spencer (1966) describe several properties of habituation that may be relevant to the use of silver vine. Weaker stimuli generally produce faster habituation, while responses to very strong stimuli may never habituate. Habituation also occurs more rapidly when less time elapses between stimulus presentations. If a response to a stimulus does become habituated, the response may spontaneously recover if the stimulus is not presented for some time. However, additional stimulus presentations after the response habituations may result in slower recovery. Finally, repeated series of habituation and spontaneous recovery may result in increasingly rapid habituation.

Previous research on habituation suggests that different amounts or concentrations of silver vine provided at different intervals may lead to different effects. A better understanding is needed to ensure that enrichment and training protocols do not unintentionally lead to a habituation of the effect of silver vine. An understanding of habituation of silver vine may also provide insight on methods to potentiate the use of silver vine as a reinforcer.

Additionally, much research on habituation has been conducted with reflexive behaviors. As silver vine produces a more diverse response than a single reflex, further research is needed to determine how the habituation of the response to silver vine compares to habituation to traditional stimuli.

\section{CONCLUSION}

In conclusion, the results of our review suggest that the potential for silver vine research and application may have been overlooked in recent years due to an unsupported but widely spread statement in the literature. We hope that the demonstration of this error and the suggested topics of research and application provoke interest in further investigation of the behavioral effects of silver vine.

\section{REFERENCES}

Baranec, T. and A. Murín, 2003. Karyological analyses of some Korean woody plants. Bio Bra., 58: 797-804.

Barrero, A.F., S. Arseniyadis, M.M. Herrador, J.F. Quílex del Moral and J.F. Arteaga et al., 2005. Sulfanyl radical-induced cyclization of linalyl acetate to the iridane skeleton: A short synthesis of (+-)-dehydroiridomyrmecin. Synlett, 2005: 591594. DOI: $10.1055 / \mathrm{s}-2005-863729$
Bashaw, M.J., M.A. Bloomsmith, M.J. Marr and T.L. Maple, 2003. To hunt or not to hunt? A feeding enrichment experiment with captive large felids. Zoo Biol., 22: 189-198. DOI: 10.1002/zoo.10065

Bernier, U.R., K.D. Furman, D.L. Kline, S.A. Allan and D.R. Barnard, 2005. Comparison of contact and spatial repellency of catnip oil and N,N-diethyl-3methylbenzamide (deet) against mosquitoes. J Med. Ento., 42: 306-311. PMID: 15962779

Bitgood, S., D. Patterson and A. Benefield, 1988. Exhibit design and visitor behaviour: Empirical relationships. Environ. Behav., 20: 474-491. DOI: 10.1177/0013916588204006

Blum, M.S., R.F. Severson, R.F. Arrendale, D.W. Whitman and P. Escoubas et al., 1990. A generalist herbivore in a specialist mode metabolic, sequestrative and defensive consequences. J. Chem. Ecol., 16: 223-244. DOI: 10.1007/ BF01021281

Boldingh, H., G.S. Smith and K. Klages, 2000. Seasonal concentrations of non-structural carbohydrates of five Actinidia species in fruit, leaf and fine root tissue. An. Bot., 85: 469-476. DOI: 10.1006/anbo.1999.1094

Chat, J., 1995. Cold hardiness within the genus Actinidia. Ho. Sci., 30: 329-332.

Chizzola, R., 2006. Volatile compounds from some wild growing aromatic herbs of the Lamiaceae from southern France. Pla. Bio.-An Int. J. Dealing Aspec. Plant Biol., 140: 206-210. DOI: 10.1080/ 11263500600756587

Clapperton, B.K., C.T. Eason, R.J. Weston, A.D. Woolhouse and D.R. Morgan, 1994. Development and testing of attractants for feral cats, Felis catus. L. Wildl. Res., 21: 389-399. DOI: 10.1071/ WR9940389

Clearwater, M., P. Blattmann, Z. Luo and R.G. Lowe, 2007. Control of scion vigour by kiwifruit rootstocks is correlated with spring root pressure phenology. J. Exp. Bot., 58: 1741-1751. DOI: 10.1093/jxb/erm029

Clearwater, M.J., A.N. Seleznyova, T.G. Thorp, P. Blattmann and A.M. Barnett et al., 2006. Vigorcontrolling rootstocks affect early shoot growth and leaf area development of kiwifruit. Tree Physiol., 26: 505-515. DOI: 10.1093/treephys /26.4.505

Clearwater, M.J., R.G. Lowe, B.J. Hofstee, C. Barclay, A.J. Mandemaker et al., 2004. Hydraulic conductance and rootstock effects in grafted vines of kiwifruit. J. Exp. Bot., 55: 1371-1382. DOI: 10.1093/jxb/erh137 
Derambure, A. and A.M. Hirsch, 1995. Obtention de protoplastes a partir de differents clones d'Actinidia deliciosa (Kiwi) et d'especes botaniques du genre Actinidia resistantes au froid. Acta Bot. Gallica., 142: 5-21.

Ellis, S., 2009. Environmental enrichment: Practical strategies for improving feline welfare. J. Feline Med. Surg., 11: 901-912. DOI: 10.1016/j.jfms. 2009.09.011

Enders, D. and A. Kaiser, 1997. Asymmetric synthesis of (R,S)-dehydroiridodial, (R,S)-dehydroiridodiol and analogues. Liebigs Ann., 1997: 485-493. DOI: 10.1002/jlac.199719970308

Frank, D., G. Beauchamp and C. Palestrini, 2010. Systematic review of the use of pheromones for treatment of undesirable behavior in cats and dogs. J. Am. Vet. Med. Assoc., 236: 1308-1316. DOI: 10.2460/javma.236.12.1308

Hayashi, T., 1968. Pseudo-affective reflexes of cats produced by extracts from the plant Actinidia polygama. Prog. Brain Res., 22: 282-285. DOI: 10.1016/S0079-6123(08)63513-X

Herron S., 2003. Catnip, Nepeta cataria, a morphological comparison of mutant and wild type specimens to gain an ethnobotanical perspective. Ecol. Bot., 57: 135-142. DOI: 10.1663/00130001(2003)057[0135:CNCAMC]2.0.CO;2

Hiramatsu, N., W. Xiufen, R. Takechi, Y. Itoh and J. Mamo et al., 2004. Antimutagenicity of Japanese traditional herbs, gennoshoko, yomogi, senburi and iwa-tobacco. BioFactors, 22: 123-125. PMID: 15630266

Hirsch, A., R. Testolin, J. Chat, D. Fortune and J. Bureau et al., 2001. Embryo rescue from interspecific crosses in the genus Actinidia (Kiwifruit). Plant Cell Rep., 20: 508-516. DOI: 10.1007/s002990100340

Hirsch, A.M., 1979. Organogenesis in two cultures of plant tissue belonging to Actinidia genus, Actinidia Chinesis and Actinidia polygama, relationship between organogenesis and peroxydase. Entreprises Agricol., 288: 1159-1162.

Hooper, A.M., B. Donato, C.M. Woodcock, J.H. Park and R.L. Paul et al., 2002. Characterization of (1R, 4S, 4aR, 7S, 7aR)-dihydronepetalactol as a semiochemical for lacewings, including Chrysopa spp. and Peyerimhoffina gracilis. J. Chem. Ecol., 28: 849-864. DOI: 10.1023/A:1015201129331

Ibrahim, H. and A. El-Moaty, 2010. Essential oil and iridoide glycosides of Nepeta septemcrenata Erenb. J. Nat. Pro., 3: 103-111.
Jung, Y.H., K.H. Kim, S.H. Kang, S.J. Jun and M.Y. Oh et al., 2003. Phylogenetic analysis of the genus Actinidia in Korea inferred from two noncoding chloroplast DNA sequences. Kor. J. Gen., 25: 95-101.

Katahira, K. and E. Iwai, 1975. Effect of unilateral lesion of amygdala on unmanifested response to Matatabi (Actinidia polygama) in cats. Tohoku. J. Exp. Med., 115: 137-143. PMID: 1129764

Katahira, K. and S. Tsukahara, 1974. Movement recording during matatabi response behavior of the cat. Fukushima. J. Med. Sci., 20: 59-65. PMID: 4442834

Katahira, K. and S. Tsukahara, 1978. A potentiometric device for recording the matatabi response of cats. Fukushima J. Med. Sci., 25: 9-13. PMID: 748138

Katahira, K., S. Tsukahara and E. Iwai, 1975. Effective stimulus cue in the matatabi response behavior of the cat. Fukushima J. Med. Sci., 21: 101-111. PMID: 1230418

Katsube, T., H. Tabata, Y. Ohta, Y. Yamasaki and E. Anuurad et al., 2004. Screening for antioxidant activity in edible plant products: Comparison of low-density lipoprotein oxidation assay, DPPH radical scavenging assay and folin-ciocalteu assay. J. Agric. Food Chem., 52: 2391-2396. DOI: 10.1021/jf035372g

Kawagoe, T. and N. Suzuki, 2004. Cryptic dioecy in Actinidia polygama: a test of the pollinator attraction hypothesis. Can. J. Bot. 82: 214-218.

Kelly, D.R., 1996. When is a butterfly like an elephant? Chem. Biol., 3: 595-606. DOI: 10.1016/S10745521(96)90125-8

Kigawa, M., M. Tanaka, H. Mitsuhashi and T. Wakamatsu, 1992. Synthesis of iridolactones isolated from silver vine. Heterocycles, 32: 117-120.

Kim, H., M.J. Song and D. Potter, 2006. Medicinal efficacy of plants utilized as temple food in traditional Korean buddhism. J. Eth., 104: 32-46. DOI: 10.1016/j.jep.2005.08.041

Kim, Y.K., H.J. Kang, K.T. Lee, J.G. Choi and S.H. Chung, 2003. Anti-inflammation activity of Actinidia polygama. Arch. Pharma Res., 26: 10611066. DOI: 10.1007/BF02994759

Lai, Y. and D.P. Xu, 2007. Study on the chemical structure from the roots of Actinidia deliciosa. Zhong Yao Cai., 30: 166-168. PMID: 17571763

Lawes, G.S., S.T. Cheong and H. Varela-Alvarez, 1995. The effect of freezing temperatures on buds and stem cuttings of Actinidia species. Scientia Horticulturae., 61: 1-12. DOI: 10.1016/03044238(94)00732-U 
Lee, S.Y., C.Y. Lee, S.H. Eom, Y.K. Kim and N.I. Park et al., 2010. Rosmarinic acid production from transformed root cultures of Nepeta cataria L. Sci. Res. Essays., 5: 1122-1126.

Lee, Y.C., S.H. Kim, Y.B. Seo, S.S. Roh and J.C. Lee, 2006. Inhibitory effects of Actinidia polygama extract and cyclosporine A on OVA-induced eosinophilia and bronchial hyperresponsiveness in a murine model of asthma. Int. Immun., 6: 703713. DOI: $10.1016 /$ j.intimp.2005.10.007

Leyhausen, P., 1973. Addictive Behavior in Free Ranging Animals. In: Psychic Dependence, Goldberg, L. and F. Hoffmiester (Eds.). Springer, New York, pp: 58-64.

Margulis, S.W., C. Hoyos and M. Anderson, 2003. Effect of felid activity on zoo visitor interest. Zoo Biol., 22: 587-599. DOI: 10.1002/zoo.10115

Markowitz, H., C. Aday and A. Gavazzi, 1995. Effectiveness of acoustic "prey": Environmental enrichment for a captive African leopard (Panthera pardus). Zoo Biol., 14: 371-379. DOI: 10.1002/zoo.1430140408

Matich, A.J., B.J. Bunn and M.B. Hunt, 2010. The enantiomeric composition of linalool and linalool oxide in the flowers of kiwifruit (Actinidia) species. Chirality, 22: 110-119. DOI: 10.1002/chir.20713

Matsuzawa, T., Y. Amano, K. Kotagiri, K. Kohno and E. Suzuki et al., 1989. Actinidia polygama maxim. tea as a source of ascorbic acid. J. Jpn. Soc. Nutr. Food Sci., 42: 191-193.

Matsuzawa, T., Y. Amano, M. Yokoyama and K. Kohno, 1986. Ascorbic acid and chemical components of Actinidia polygama maxim tea. J. Jpn. Soc. Nutr. Food Sci., 39: 63-66.

McCaskill, D. and R. Croteau, 1997. Prospects for the bioengineering of isoprenoid biosynthesis. Biotechnol. Aroma Compou., 55: 107-146. DOI: 10.1007/BFb0102064

McGhie, T.K. and G.D. Ainge, 2002. Color in fruit of the genus Actinidia: Carotenoid and chlorophyll compositions. J. Agric. Food Ch., 50: 117-121. DOI: $10.1021 /$ jf0106771

Mellen, J.D. and D.J. Shepherdson, 1997. Environmental enrichment for felids: An integrated approach. Int. Zoo Yearb, 35: 191-197. DOI: 10.1111/j.1748-1090.1997.tb01209.x

Otsuka, H., E. Hirata, T. Shinzato and Y. Takeda, 2003. Stereochemistry of megastigmane glucosides from Glochidion zeylanicum and Alangium premnifolium. Phytochemistry, 62: 763-768. DOI: 10.1016/S0031-9422(02)00614-3
Patocka, J. and J. Jakl, 2010. Biomedically relevant chemical constituents of Valeriana officinalis. J. Applied Biol., 8: 11-18.

Powell, D.M., 1995. Preliminary evaluation of environmental enrichment techniques for African lions (Panthera leo). Anim. Wel., 4: 361-370.

Ren, J., E.J. Han and S.H. Chung, 2007. In vivo and in vitro anti-inflammatory activities of alpha-linolenic acid isolated from Actinidia polygama fruits. Arch Pharm Res., 30: 708-714. PMID: 17679548

Sakai, T., K. Nakajima, K. Yoshihara, T. Sakan and S. Isoe, 1980. Revisions of the absolute configurations of C-8 methyl groups in dehydroiridodiol, neonepetalactone and matatabiether from Actinidia polygama miq. Tetahedron., 36: 31153119. DOI: $10.1016 / 0040-4020(80) 88041-0$

Santangelo, E.M., D. Rotticci, I. Liblikas, T. Norin and C.R. Unelius, 2001. Resolution of an iridoid synthon, gastrolactol, by means of dynamic acetylation and lipase-catalyzed alcoholysis. J. Org. Chem. 66: 5384-5387. DOI: 10.1021/jo 015592y

Sashida, Y., K. Ogawa, N. Mori and T. Yamanouchi, 1992. Triterpenoids from the fruit galls of Actinidia polygama. Phytochemistry, 31: 2801-2804. DOI: 10.1016/0031-9422(92)83634-B

Sashida, Y., K. Ogawa, T. Yamanouchi, H. Tanaka and Y. Shoyama et al., 1994. Triterpenoids from callus tissue of Actinidia polygama. Phytochemistry, 35: 377-380. DOI: 10.1016/S0031-9422(00)94767-8

Shepherdson, D.J., 1998. Tracing the Path of Environmental Enrichment in Zoos. In: Second Nature: Environmental Enrichment for Captive Animals. Shepherdson, D.J., J.D. Mellen and M. Hutchins, (Eds.). Smithsonian Institution Press, London, pp: 1-12.

Sheperdson, D.J., K. Carlstead, J.D. Mellen and J. Seidensticker, 1993. The influence of food presentation on the behavior of small cats in confined environments. Zoo Biol., 12: 203-216. DOI: 10.1002/zoo.1430120206

Shoyama, Y., S. Chen, H. Tanaka, Y. Sasaki, and Y. Sashida, 1998. Actinidia polygama (Japanese name matatabi): In vitro culture, micropropagation, and the production of monoterpenes and triterpenoids. In: Biotechnology in Agriculture and Forestry 41: Medicinal and Aromatic Plants X, Bajaj, Y.P.S., (Eds.). Springer-Verlag, Berlin. ISBN-10: 3540627278. pp: 1-13. 
Shyne, A., 2006. Meta-Analytic review of the effects of enrichment on stereotypic behavior in zoo mammals. Zoo Biol., 25: 317-337. DOI: 10.1002/zoo.20091

Skaltsa, H.D., D.M. Lazari, A.E. Loukis and T. Constantinidis, 2000. Essential oil analysis of Nepeta argolica Bory and Chaub. subsp. argolica (Lamiaceae) growing wild in Greece. Fla. Fra. J., 15: 96-99. DOI: 10.1002/(SICI)1099-1026(200003 /04)15:2<96::AID-FFJ873>3.0.CO;2-F

Skibel, A.L., H.S. Trevino and K. Naugher, 2007. Comparison of several types of enrichment for captive felids. Zoo Biol., 26: 371-381. DOI: 10.1002/zoo.20147

Sugawara, F., N. Yamamoto and O. Tanaka, 1994. Plant regeneration in in vitro culture of leaf, stem and petiole segments of Actinidia polygama miq. Plant Tissue Culture Letters, 11: 14-18.

Sulaiman, B.H. and J. Yukawa, 1992. Relationship between inhabitants and size or weight of galls caused by Pseudasphondylia matatabi (Diptera: Cecidomyiidae). Proc. Assoc. Pl. Prot. Kyushu., 38: 186-189.

Takazawa, H., K. Yoshimura, A. Ikuta and K. Kawaguchi, 2002. Production of triterpenes from the callus tissues of actinidiaceous plants. Plant Biotechnol., 19: 181-186. DOI: 10.5511/plant biotechnology.19.181

Tanaka, H., Y. Shoyama, Y. Sasaki and Y. Sashida, 1997. Micropropagation of Actinidia polygama from fruit galls. Plant Cel. Tiss. Org. Culture., 48: 135-137. DOI: 10.1023/A:1005806607349

Tarou, L.R. and M.J. Bashaw, 2007. Maximizing the effectiveness of environmental enrichment: Suggestions from the experimental analysis of behavior. Applied Anim. Behav. Sci., 102: 189204. DOI: $10.1016 /$ j.applanim.2006.05.026

Thompson, R.F. and W.A. Spencer, 1966. Habituation: A model phenomenon for the study of neuronal substrates of behavior. Psychol. Rev., 73: 16-43. DOI: $10.1037 / \mathrm{h} 0022681$

Tucker, A.O. and S.S. Tucker, 1988. Catnip and the catnip response. Econ. Bot., 42: 214-231. DOI: 10.1007/BF02858923

Webby, R.F., R.D. Wilson and A.R. Ferguson, 1994. Leaf flavonoids of Actinidia. Biochem. Syst. Ecol., 22: 277-286. DOI: 10.1016/0305-1978(94)90101-5
Weldon, P.J., 2004. Defensive anointing: extended chemical phenotype and unorthodox ecology. Chemoecology, 14: 1-4. DOI: 10.1007/s00049003-0259-8

Wuest, J.D., A.M. Madonik and D.C. Gordon, 1977. Vinylketenes. Synthesis of (+)- actinidine. J. Org. Chem., 42: 2111-2113. DOI: 10.1021/jo00432a019

Xiao, X.G. and A.M. Hirsch, 1996. Microcallus formation from leaf mesophyll protoplasts in the genus Actinidia lindl. Plant Cell Reports, 15: 896899. DOI: $10.1007 / \mathrm{BF} 00231583$

Xiufen, W., N. Hiramatsu and M. Matsubara, 2004. The antioxidative activity of traditional Japanese herbs. BioFactors, 21: 281-284. DOI: 10.1002/biof. 552210155

Yoshizawa, Y., H. Todoh, A. Ametani and S. Kaminogawa, 1994. Mouse phagocyte-stimulating substances from seaweeds and herbs. J. Food Sci. Technol., 41: 557-560.

Yoshizawa, Y., S. Kawaii, M. Urashima, T. Fukase and T. Sato et al., 2000a. Antiproliferative effects of small fruit juices on several cancer cell lines. Anticancer Res., 20: 4285-4290. PMID: 11205259

Yoshizawa, Y., S. Kawaii, M. Urashima, T. Fukase and T. Sato et al., 2000b. Differentiation-inducing effects of small fruit juices on HL-60 leukemic cells. J. Agric. Food Chem., 48: 3177-3182. DOI: 10.1021/jf9908650

Yoshizawa, Y., Y. Fukiya, Y. Izumi, K. Hata and J. Iwashita et al., 2002. Induction of apoptosis with an extract of Actinidia polygama fruit in the promyelocytic leukemia cell line HL-60. J. Health Sci., 48: 303-309. DOI: 10.1248/jhs.48.303

Zhao, Y.P., X.Y. Wang, Z.C. Wang, Y. Lu and C.X. Fu et al., 2006. Essential oil of Actinidia macrosperma, a catnip response kiwi endemic to China. J. Zhe. Univ-Sci B, 7: 708-712. DOI: 10.1631/jzus. 2006. B0708

Zhao, Y.P., Y.X. Qui, W. Gong, J.H. Li and C.X. Fu, 2007. Authentication of Actinidia macrosperma using PCR-RFLP based on trnK sequence. Bot. Stud., 48: 239-242. 